\title{
A QUÍMICA AMBIENTAL NO BRASIL
}

\author{
Antonio A . Mozeto* \\ Departamento de Química, Universidade Federal de São Carlos, CP 676, 13565-905 São Carlos - SP \\ Wilson de F. Jardim \\ Instituto de Química, Universidade Estadual de Campinas, CP 6154, 13083-970 Campinas - SP
}

\begin{abstract}
ENVIRONMENTAL CHEMISTRY IN BRASIL. Defining environmental chemistry is a not an easy task because it encompasses many different topics. According to Stanley E. Manahan, author of a classical textbook of Environmental Chemistry, this branch could be defined as the one centered in the study of the sources, transport, effects and fates of chemical species in the water, soil, and air environments, as well as the influence of human activity upon these processes. More recently, new knowledge emerged from the Environmental Toxicology allowed to go even deeper in the meaning of 'effects' and 'fates' of a continuous growing number of organic and inorganic species disposed in water bodies, soils and atmosphere. Toxicity tests became an important tool to evaluate the environmental impact of such species to a great number of organisms, thus allowing to set quality criteria for drinking water, sediments and biota. The state of art shows that environmental chemistry is a multi-inter disciplinary science by nature; therefore, it needs more than a limited, unique-approach and non-oriented set of data to understand the nature of natural processes. Taking all these aspects into consideration, one can say that Environmental Chemistry in Brazil is now a well established area of research within the classical areas of the Chemistry, with a large number of emerging groups as well research groups with worldwide recognition.
\end{abstract}

Keywords: environmental chemistry; SBQ; environmental chemistry division.

\section{INTRODUÇÃO}

Em termos ambientais, pode-se dizer que estas últimas duas décadas foram marcadas, no Brasil, por um crescendo de conscientização dos cidadãos e empresas sobre os danos causados por uma verdadeira miríade de atividades humanas, quer nas suas mais elementares atividades em seus lares, quer naquelas industriais. Grande parte dessas atividades tem gerado efluentes e resíduos, sólidos, líquidos e gasosos que, de uma maneira ou outra, têm seu destino final na atmosfera, nos solos e nos corpos d'água, lóticos e lênticos, naturais e artificiais, continentais, costeiros ou nos oceanos. Um grande número desses efluentes e resíduos constituem-se em materiais ricos em nutrientes (carbono, nitrogênio e fósforo) e contaminantes orgânicos (aqui, uma variedade realmente grande existe) e inorgânicos (metais e metalóides) que são os responsáveis pelos muitos males que nossos ecossistemas vêm sofrendo e, outros muitos que atingem aos homens.

Neste mesmo período, consolidou-se a recém criada Sociedade Brasileira de Química (SBQ), abrigando um número cada vez maior de sócios vindos de diversas instituições de ensino e pesquisa, bem como do parque industrial do país. No início da década passada (1994), dentre outras divisões, foi criada a Divisão de Química Ambiental com o propósito de abrigar a produtividade técnica e científica de uns não muitos técnicos e pesquisadores que já, há alguns anos, militavam nesta área de concentração e outras congêneres ou afins. Conforme consta do editorial contido na página URL da Divisão "A Química Ambiental, assim como qualquer outra área clássica da Química, pode ser definida de várias maneiras. Para nós, a Química Ambiental estuda os processos químicos que ocorrem na natureza, sejam eles naturais ou ainda causados pelo homem, e que comprometem a saúde humana e a saúde do planeta como um todo. Assim, dentro desta definição, a Química Ambiental não é a ciência da

\footnotetext{
*e-mail: amozeto@dq.ufscar.br
}

monitoração ambiental, mas sim da elucidação dos mecanismos que definem e controlam a concentração das espécies químicas candidatas a serem monitoradas".

As iniciativas de projetos de pesquisa na área adquirem então, um caráter mais inter-multidisciplinar pois passam a ser desenvolvidos em cooperação com diversos outros profissionais da biologia, ecologia e geologia, dentre outros. Houve também neste período, um marcante avanço no reconhecimento do arcabouço da legislação ambiental, mais proeminentemente, por parte dos pesquisadores e educadores da área, e em menor extensão, por parte da sociedade civil e das empresas. No que tange à Divisão de Química Ambiental da SBQ, ocorreu então, uma definição mais apurada do que se entende por Química Ambiental, onde os trabalhos submetidos às Reuniões Anuais (RA's) passaram a ser selecionados fundamentalmente, com base no paradigma do contexto ou da problemática ambiental definidos e não como simples trabalhos de monitoração ambiental. Tem havido nos últimos anos, finalmente, consenso de que estes últimos trabalhos são próprios dos órgãos de controle e fiscalização ambiental das esferas municipal, estadual e federal e não das universidades e institutos de pesquisa que, fundamentalmente, executam pesquisas básicas e aplicadas na área, forte e claramente, contextualizadas em problemas ambientais definidos, e de preferência, tendo-se um ecossistema ou, um ou mais de seus compartimentos, enfocados. Nasceu daí, portanto, a conotação fortemente multi e interdisciplinar desses projetos de pesquisa.

Num artigo editorial do periódico ES\&T (Enviromental Science and Technology) da ACS (American Chemical Society) de 1994 ${ }^{1}$, o editor-chefe discorre sobre a aprovação da área de Química Ambiental nos cursos de bacharelado em Química nos EUA dada a grande importância desta área para aquela nação e dado o grande interesse despertado junto ao alunado. Reporta-se que os trabalhos publicados neste veículo nas décadas de 60 e 70 eram bastante descritivos. Publicavam-se estudos (apenas) sobre níveis de contaminação de certos lugares, para os quais muitas vezes pouco se ia além da análise estatística dos dados; outros trabalhos, restringiam-se a adapta- 
ções de métodos no estudo de um 'sistema ambiental' (aspas nossas). Este mesmo 'fenômeno' também era lugar comum aqui no Brasil (ainda alguns dão crédito ao mesmo), qual seja, supõe-se estar praticando química ambiental quando se está analisando uma 'matriz ou amostra ambiental'. O mesmo editorial da ES\&T citado acima reporta que da década de 60/70 a 1994, teria ocorrido uma melhoria na qualidade dessas publicações dada a evolução significativa dos métodos analíticos disponíveis nos laboratórios e a evolução no reconhecimento da área por um número cada vez maior de pesquisadores que haviam descoberto a diferença entre os sistemas de laboratórios (puros e limpos) em comparação aos naturais (muito mais complexos).

\section{PREMISSAS DA QUÍMICA AMBIENTAL MODERNA (Ensino e Pesquisa)}

A Química Ambiental é, hoje, reconhecida como o maior e mais natural exemplo da inter multidisciplinaridade da Química como ciência exata. Desta forma, quer os projetos de pesquisa na área de concentração, quer no ensino e avaliação da mesma, não se deve adotar uma abordagem reducionista. Não se deve esquecer que, em última análise ou a razão de ser desta disciplina, é ou são os ecossistemas, seus compartimentos abióticos e bióticos. Todas as questões abordadas que digam respeito a processos naturais e/ou afetados por ações antópicas, quer da atmosfera, hidrosfera e geosfera/pedosfera, têm de ser tratadas de forma holística ou integrada.

Isto equivale a dizer que a conceituação (teoria) que está por trás de cada cálculo matemático que se faça, isto é, os significados dos números que são levantados nas medidas de campo e laboratório ou computações que fazemos a todo momento, assume magistral importância. Não basta gerarem-se números ou resultados analiticamente precisos e exatos, se não se tem conhecimento dos significados biogeoquímicos e ecológicos dos mesmos.

Novamente cabe recorrer aqui ao Editorial que se encontra na página da Divisão que aborda o seguinte ponto "Dentro desta premissa, a Química Ambiental expande os horizontes da química convencional dando a ela uma dimensão socio-econômica, além de propiciar parcerias encantadoras com outras áreas do conhecimento como a toxicologia, a engenharia sanitária e a biologia. Sendo assim praticada, a Química Ambiental revive a Química como uma ciência natural, atua como vetor de sua descompartimentalização e certamente deve ser encarada como a ferramenta mais poderosa no resgate da importância da Química como uma das ciências que mais benefícios tem trazido ao homem."

Uma das literaturas-chave que definiu pela primeira vez grandes postulados (ou 'máximas') da Química Ambiental como ciência que a difere da Química Clássica é o livro Química Aquática de W. Stumm \& J. Morgan, editado pela primeira vez em $1976{ }^{2}$. Algumas das principais postulações desta verdadeira 'bíblia' da Química Ambiental são descritas a seguir dada a importância que têm na própria definição da área.

\section{Dualidade natureza $\mathbf{x}$ laboratório}

A natureza dos fenômenos na biosfera apresenta uma discrepância com os fenômenos de laboratório; aqueles, são irreversíveis ou de não-equilíbrio por natureza, ou ainda cinéticos, enquanto que estes, são reversíveis ou de equilíbrio ou ainda, termodinâmicos. O caso que mais contundentemente exemplifica ou esclarece esta máxima, é a constatação do seqüencial de reações redox típica de ambientes aquáticos, do qual participam diversos elementos redox-sensíveis como o $\mathrm{C}, \mathrm{H}, \mathrm{O}, \mathrm{N}, \mathrm{S}, \mathrm{Fe}$ e $\mathrm{Mn}$. A grande maioria desses processos ou são diretamente ou indiretamente mediados por mi- crorganismos. A ciclagem biogeoquímica do enxôfre é, talvez, o melhor exemplo de todos. A base desta seqüência de reações é a oxidação da matéria orgânica, quer por via aeróbia ou anaeróbia que acontece rotineiramente nas colunas d'água e sedimentos dos ambientes aquáticos, nos aterros sanitários e nos reatores de tratamento de efluentes.

\section{$O$ poder das interfaces}

A rigor, muitos dos processos de troca de prótons (ácido-base), de elétrons (redox), de complexação (de um íon metálico por ligantes orgânico ou inorgânico), precipitação (recristalização/dissolução) etc, acontecem na superfície das partículas sólidas (na realidade, de natureza mista, orgânica e inorgânica) ou na interface destas e a água. Estes temas têm ganho grande atenção em pesquisa nos últimos anos gerando uma área que se convencionou chamar de 'biofilme' dada as dimensões moleculares que têm.

Estas interfaces assumem, fisicamente, outras conotações e dimensões, como por exemplo, as interfaces água-ar e sedimento-água. Muito do conhecimento da ciclagem de nutrientes e contaminantes que detemos hoje foi adquirido porque nos habilitamos a determinar fluxos desses elementos nestas interfaces. O Químico Ambiental, em especial os aquáticos, sabem muito bem o significado e o valor (ambos interpretativos) de se ter em mãos 'apenas' o valor da concentração de um dado analito (numa dada matriz, digamos, água) que representa 'apenas', o 'standing crop químico' (algo totalmente estático), enquanto que os fluxos, representam (ou são parte muito importante) a dinâmica de um ambiente em estudo.

\section{A questão da especiação química}

É uma questão da maior relevância dado que o seu conhecimento pode ter implicações diretas ou indiretas com uma das questões mais relevantes da Química Ambiental moderna que é a toxicologia, humana ou ambiental (ou ecotoxicologia). Isto porque, não raras vezes, a especiação química é o instrumento que mais subsidia a avaliação da toxicidade de certas espécies químicas; num primeiro plano, está evidentemente, a toxicidade destas espécies químicas e organismos vivos que vivem nas águas e/ou sedimentos dos ambientes aquáticos em questão e num plano mais avançado, está a questão da toxicologia humana, isto é, saúde pública per se. A abordagem destas questões é de vital importância para a Química Ambiental moderna porque, em última análise ou por trás de todo estudo detalhado e sistemático que se realiza ou do grande volume de dados e informações que usualmente se levanta num projeto de pesquisa, a coisa mais importante e que está no fim desta cadeia de eventos e atividades, é a questão da saúde pública. Por esta única razão justificam-se o esforço e os custos de pesquisa em se realizar estudos de especiação de elementos, especialmente para aqueles reconhecidamente suspeitos de serem deletérios não só às comunidades biológicas do meio ambiente (zooplancton, organismos bentônicos e peixes, por exemplo), mas a nós próprios.

No escopo de se ter projetos de pesquisas e disciplinas na área da Química Ambiental que se enquadrem numa visão holística seria fundamental que, sempre que possível, fossem abordados os seguintes pontos: (a) descrição do funcionamento (incluindo-se o ecológico) natural ou de base do ecossistema ou de um ou mais de seus reservatórios (ou compartimentos) e suas possíveis alterações (os impactos ambientais negativos) em função das atividades antrópicas em consideração; (b) ter como base ou em considerando um ou mais estudos-de-casos similares ao problema em estudo; (c) incluir e discutir as legislações ambientais pertinentes e todas as implicações do ponto de vista legal; (d) incluir e discutir as questões toxicológicas, 
quer do ponto de vista de comunidades aquáticas e/ou terrestres e as relativas à saúde humana; (e) discutir o problema de forma integrada do ponto de vista das interações abióticas, bióticas, sócio-econômicas e culturais; (f) estar sempre atento às situações do estado-da-arte o mais atual possível com base em literatura o mais recente possível; (g) tratando-se de um processo industrial ou agro-industrial e/ou de tratamento de efluentes ou resíduos em que haja a geração de um outro resíduo e/ou efluente, discutir a forma correta de tratamento, caracterização e classificação segundo normas e leis ambientais vigentes no Brasil; (h) considerar que o tratamento de resíduos é uma opção remediativa, e que a opção mais harmoniosa ambientalmente é a minimização na produção de rejeitos; (i) as escalas dos fenômenos em consideração: local, regional ou global, bem como considerando-se também a bacia hidrográfica e atmosférica (ou aérea) em consideração ou como base para o desenvolvimento de pesquisa.

\section{O ENSINO DA QUÍMICA AMBIENTAL NO BRASIL}

Existe um consenso sobre o fato de que só se pode ensinar aquilo que se sabe. É importante resgatar este ditado porque ele explica, em grande parte, o que ocorreu com a difusão do ensino da Química Ambiental no Brasil e os fatos decorrentes desta realidade, os quais criaram alguns falsos paradigmas dentro desta área, e que até hoje são combatidos com veemência. $\mathrm{O}$ cenário que se descortinava na década de 80 no nosso país era o de uma grande demanda pelos assuntos voltados à química do meio ambiente, enquanto que o Brasil possuía pouquíssimos profissionais que haviam sido formados e devidamente treinados dentro desta temática.

Para suprir esta lacuna, na década de 80 surgem as primeiras disciplinas de Química Ambiental nos cursos de graduação em Química, as quais se caracterizavam por ementas das mais diversificadas que se poderia imaginar. Parte disso se deveu ao fato de que havia muito pouco material didático disponível sobre o tema, sendo que nenhum deles em português. Cabe lembrar aqui que, muito embora a oferta de livros-textos sobre Química Ambiental tenha sido pelo menos quadruplicada nestes 20 anos, ainda temos uma carência muito grande de material na nossa língua-mãe. Esta falta de conhecimento sobre o que ensinar fez com que, em alguns cursos de Química, a ementa de Química Ambiental fosse uma colcha de retalhos, abordando assuntos dos mais variados, indo desde o relato de experiências de antropologia, passando pela clássica palestra com o chefe do Corpo de Bombeiros, e finalmente encerrando o semestre com uma visita informal a uma fábrica de cerveja ou a um lixão no bairro próximo à Universidade. Essa estratégia de ensino promovia a pulverização do conteúdo programático da disciplina através da realização de palestras de convidados que, muitas vezes, uma tinha pouco ou nada a ver com as outras.

Deste modo, os alunos (e uma grande parte dos ensinadores) tinham uma visão totalmente deturpada do que era Química Ambiental, o que explica, em parte, o grande desafio das primeiras diretorias da Divisão em falar uma linguagem única com a comunidade científica.

Em 1989 é publicado na Química Nova ${ }^{3}$ um artigo que abordava o problema do conteúdo a ser explorado numa disciplina de Química Ambiental, juntamente com uma proposta de ementa baseada no estudo dos reservatórios, e não na ciclagem dos elementos. Muito embora este artigo pudesse ter servido como base para a renovação e implementação da disciplina, ainda o grande entrave era (e, de certo modo ainda o é) o material didático a ser usado.

Em 1992, por ocasião da $2^{\text {a }}$ Conferência das Nações Unidas para o Meio Ambiente e Desenvolvimento (ECO 92), a Comissão de Meio Ambiente da SBQ (note que a Divisão de Química Ambiental ainda não existia) publica um número especial da Química Nova dedicado ao tema. Este volume foi, sem dúvida, a primeira coletânea de trabalhos voltados para um diagnóstico de problemas ambientais no Brasil, versando sobre os mais diversos temas, tais como atmosfera, águas interiores, sistemas costeiros, pesticidas, exposição ocupacional, garimpos e biodiversidade. Este número traz também um resgate histórico dos mais importantes, até aquela data, sobre a pesquisa em Química Ambiental no Brasil 4 .

Nestes últimos cinco anos, com a disseminação da rede mundial internet, o acesso à informação ficou muito facilitado e, pode-se dizer, democratizado, uma vez que o custo da informação também ficou muito mais acessível. Deste modo, encurtaram-se os grandes abismos entre as universidades de todo mundo, permitindo a difusão e o intercâmbio de um certo tipo de conhecimento específico desta área. Se, por um lado, a oferta da informação explodiu neste final de século, a qualidade e a fidedignidade das mesmas carece de uma análise crítica, principalmente no tocante à questão ambiental.

Por iniciativa da SBPC (Sociedade Brasileira para o Progresso da Ciência), o periódico Ciência e Cultura publicou em seu volume 49/janeiro-abril de $1997^{5}$ um conjunto de 11 artigos dedicados à discussão de alguns problemas ambientais do Brasil. Este volume especial trouxe uma contribuição significativa, quer do ponto de vista dos projetos de pesquisas representativos do país daquela época, quer do educacional, uma vez que a discussão dos vários estudos em questão (remediação de ambientes contaminados por compostos orgânicos voláteis; estudos biogeoquímicos em áreas alagáveis naturais; impactos ambietais do desmatamento em substituição à agricultura e pastagem nas ciclagens de elementos; contaminação mercurial atmosférica e de peixes; dentre outros) têm servido como material didático valioso a muitos educadores e educandos.

Mais recentemente, a Divisão de Ensino da SBQ lança uma série de cadernos temáticos (Química Nova na Escola) para justamente suprir a falta de material didático no nosso país. Dos cinco temas escolhidos, o volume dedicado à Química Ambiental ${ }^{6}$ alcança um sucesso sem precedentes pois traz em uma linguagem bastante simples e bem fundamentada sob o ponto de vista científico, cinco artigos sobre os principais processos químicos que ocorrem na atmosfera, nos corpos aquáticos e nas estações de tratamento de resíduos sólidos e líquidos.

A iniciativa deste periódico é das mais elogiosas e mostra, dentre outras coisas, que a comunidade de Químicos Ambientais do país quando motivada/incentivada, responde positivamente. Seria altamente e igualmente positivo se, não só a SBQ, mas outras entidades de pesquisa e ensino, bem como grupos de pesquisas que enfocam diferentes sub-áreas da Ambiental, grupos de técnicos ligados ao setor industrial etc, dessem prioridade à produção de materiais didáticos no estilo deste da Química Nova na Escola.

\section{A DIVISÃo DE QUÍMICA AMBIENTAL NA SBQ}

A criação da divisão ocorreu no ano de 1994, sendo a sua primeira diretoria interina ocupada por convite e indicação da diretoria da SBQ pelos Profs. Drs. Antonio A. Mozeto (UFSCar) e Antonio H. Miguel (IQ-USP), a qual atuou por pouco mais de um ano. Para o biênio 1994-96 foi eleita a primeira diretoria composta pelos Profs. Drs. Antonio A. Mozeto (presidente, UFSCar) e Wilson de F. Jardim (vice-presidente, UNICAMP). Subseqüientemente, a Divisão elegeu os seguintes Profs. Drs. como Presidentes: 1996-98: Júlio C. Rocha (UNESP-Araraquara); 1998-2000: Lilian R. Carvalho (USP-São Paulo); 2000-2002: Marco Tadeu Grassi (UFPR). No início do ano de 2002, a divisão contava com 220 afiliados.

Como participação de seus afiliados, a Tabela 1 mostra a evolução história de trabalhos científicos aprovados e apresentados nas RA's da SBQ, da $18^{\mathrm{a}}$ à $24^{\mathrm{a}}$. Ao se analisar a Reunião realizada em 
2001, nota-se que as 17 divisões relacionadas com a Química enviaram um total de 1470 artigos. A Divisão de Química Ambiental contribuiu com $6,3 \%$ deste total, o que é um número expressivo tendo em vista o número relativamente baixo de pesquisadores da área.

Tabela 1. Número de trabalhos publicados pela Divisão de Química Ambiental na reuniões Anuais da SBQ de 1995 a 2001

\begin{tabular}{lcc}
\hline RA's & Ano & $\begin{array}{c}\text { No. trabalhos } \\
\text { aprovados }\end{array}$ \\
\hline $24^{\mathrm{a}}$ & 2001 & 92 \\
$23^{\mathrm{a}}$ & 2000 & 113 \\
$22^{\mathrm{a}}$ & 1999 & 90 \\
$21^{\mathrm{a}}$ & 1998 & 97 \\
$20^{\mathrm{a}}$ & 1997 & 71 \\
$19^{\mathrm{a}}$ & 1996 & 64 \\
$18^{\mathrm{a}}$ & 1995 & 68 \\
\hline
\end{tabular}

A comunidade de químicos ambientais do país tem também contribuído de modo surpreendentemente positivo junto aos já consagrados Encontros Nacionais de Química Analítica (ENQA's), que congregam a comunidade brasileira de químicos analíticos. A Tabela 2 dá conta dessas contribuições dos três últimos encontros. Nestes últimos 6 anos, em termos médios, essa contribuição tem sido de aproximadamente $19 \%$ do total de trabalhos apresentados nestes encontros, que congregam trabalhos em cerca de 12 sub-áreas. Embora não se disponha do número total de trabalhos submetidos para análise, percebe-se também que esta contribuição evoluiu de cerca de 15 a $23 \%$ nestes últimos 6 anos.

Tabela 2. Variação percentual do número de trabalhos publicados pela área de Química Ambiental nos três últimos Encontros de Química Analítica (ENQA)

\begin{tabular}{lccc}
\hline ENQA's & $\begin{array}{c}\text { Total de } \\
\text { trabalhos }\end{array}$ & $\begin{array}{c}\text { Química } \\
\text { Ambiental }\end{array}$ & $\begin{array}{c}\% \text { do } \\
\text { total }\end{array}$ \\
\hline $9^{\circ}$ & 356 & 53 & 14,9 \\
$10^{\circ}$ & 462 & 95 & 20,6 \\
$11^{\circ}$ & 421 & 96 & 22,8 \\
\hline
\end{tabular}

Também como um parâmetro de produtividade da comunidade de Químicos Ambientais do país, deve-se citar uma importante reunião realizada na UNICAMP, Campinas-SP, em fevereiro/1990, ao que se denominou 'Encontro de Química Ambiental: Diagóstico e Perspectivas', cuja organização ficou ao cargo do Laboratório de Química Ambiental do IQ-UNICAMP (Prof. Wilson de F. Jardim). Neste encontro foram realizadas 10 palestras e 3 mesas-redondas com a participação de pesquisadores convidados que versavam sobre vários temas da área de concentração.

De 1990 para cá, exceto pelas Reuniões Anuais da SBQ onde a Divisão da Ambiental promove a união dos químicos ambientais do país através de apresentação de expressivo número de painéis, apresentações orais de trabalhos selecionados em sessões coordenadas e de palestras de convidados (geralmente externos à Divisão e à SBQ), não se repetiu a dose da reunião de Campinas acima citada. Há, presentemente, a perspectiva da realização de um workshop similar em futuro próximo (ano de 2002) na UnB, Brasília - DF, que sem dúvida, virá preencher esta inquietante lacuna e que muito contribuirá para que o futuro da Química Ambiental no Brasil seja realmente promissor, como é a expectativa de todos.

\section{QUADRO ATUAL E PERSPECTIVAS FUTURAS}

Um olhar sobre a evolução histórica da Química Ambiental mostra que a mesma ocupa hoje um cenário de grande destaque na vida científica do Brasil, além de ter conseguido uma projeção internacional que poucas áreas da Química conseguiram. No entanto, o caminho não foi fácil. No Brasil, a Química Analítica tinha se firmado através de uma escola tradicional, muito mais voltada para a elucidação de uma química definida dentro do laboratório do que para os fenômenos que ocorriam fora dele. Assim, o país tinha muito pouca tradição em químicos com experiência em trabalhos ambientais, incluindo trabalhos de campo e amostragem ambiental.

Como grande parte dos químicos que hoje atua na área de meio ambiente tinha uma forte ligação com a (e também uma formação básica em) Química Analítica, pode-se dizer que esta área da Química demorou a tomar vulto no nosso país se comparada a outras academias na Europa e na América do Norte. No entanto, percebe-se que esta demora não trouxe maiores problemas, nem deixou sequielas que prejudicaram o desenvolvimento desta área, muito embora ainda exista uma forte superposição da Química Ambiental com a Química Analítica Ambiental no Brasil.

A Química Ambiental tem hoje um papel importante no diagnóstico de problemas ambientais no nosso país, sejam eles de abrangência local, regional, continental e mesmo global, bem como tem atuado de modo cada vez mais ativo na solução destes problemas. Os poucos grupos estabelecidos que existiam no início da década de 90 (menos de uma dezena deles) e que se concentravam principalmente nas mais tradicionais universidades brasileiras, hoje compartilham o mesmo espaço com inúmeros grupos emergentes e atuantes, espalhados por todo o país. A partir do momento que houver uma maior interação com o Poder Legislativo, de modo que estes pesquisadores possam efetivamente colaborar na elaboração e aprimoramento das políticas públicas voltadas para a questão ambiental, pode-se dizer que a Química Ambiental terá cumprido plenamente o papel que hoje se espera das universidades e da comunidade científica brasileira.

Há, evidentemente, outros problemas para a efetiva consolidação de grupos emergentes distribuídos pelo Brasil e o principal deles depende de um plano continuado de fomento à pesquisa, quer no que tange aos projetos de pesquisa ou na formação de recursos humanos especializados. Embora este problema seja menos agudo no Estado de São Paulo dada a excelência dos programas da FAPESP, outros grupos espalhados pelo Brasil (especialmente aqueles grupos das regiões Centro-Oeste, Nordeste e Norte do país) estão vivendo em situação de verdadeira 'penúria científica' pois dependem de apoio do Governo Federal (CNPq, MCT e outros programas). Quando dispõem por exemplo de alguma infraestrutura de laboratório (i.e., equipamentos especializados para suas análises), não dispõem de pessoal técnico treinado não só em técnicas analíticas mas, talvez mais principalmente, em fundamentos da área para fazer face a uma interpretação ambiental em sintonia com os problemas estudados. Muito embora o recente aporte de recursos oriundos dos fundos setoriais possa amenizar este quadro, isto ainda não é a solução definitiva para o problema.

Finalmente, caberia apontar para o fato da incoerência que transparece de modo muito claro quando se analisa a estrutura das agências de fomento à pesquisa no Brasil, sejam elas estaduais ou federais. Muito embora a Química Ambiental tenha sido uma das áreas que mais cresceu e se consolidou dentro da Química nesta última década, fatos estes reconhecidos nos discursos de toda a nossa comunidade, na prática, ela ainda não conquistou seu lugar nos Comitês Assessores destas agências, o que implica em assumir que grande parte dos projetos de pesquisa voltados para este tema estão sendo analisados por pares que podem não ter uma formação específica na área. 


\section{REFERÊNCIAS}

1. Editorial; Environ. Sci. Tech. 1994, 28, 169A.

2. Stumm, W.; Morgan, J.J.; Aquatic Chemistry. An Introduction Emphasizing Chemical Equilibria in Natural Waters, 1976, John Wiley \& Sons: New York.

3. Jardim, W. F.; Quim. Nova 1989, 12, 291

4. de Andrade, J.B.; Quim. Nova 1992, 15, 173.

5. Ciência e Cultura 1997, 49, 13-120.

6. Química Nova na Escola, Caderno Temático de Química Ambiental, 2001, n. 1, 3-49.

\section{APÊNDICE}

\section{DIVISÃO DE QUÍMICA AMBIENTAL}

Número de filiados: 220 (atual)

1994

DIRETORES

Antonio A. Mozeto e Antonio H. Miguel

INTERINOS:

1994-1996

DIRETOR:

VICE-DIRETOR:

Antonio A. Mozeto

TESOUREIRO:

Wilson de F. Jardim

cargo ficou vago

1996-1998

DIRETOR:

Júlio C. Rocha

VICE-DIRETOR:

Maria Olímpia O. Rezende

TESOUREIRO:

José Roberto Guimarães

1998-2000

DIRETOR:

Lilian R. Carvalho

VICE-DIRETOR: Luiz A. Madureira

TESOUREIRO:

Pedro Afonso de P. Pereira

2000-2002

DIRETOR:

VICE-DIRETOR:

Marco Tadeu Grassi

Wilson de F. Jardim

TESOUREIRO:

Márcia M. Kondo 